\title{
Information Seeking Behavior in Blind People of Iran : a Survey based on Various Experiences faced by them
}

\section{Hasan Siamian ${ }^{1 *}$, Mohammad Hassanzadeh², Fatemeh Nooshinfard ${ }^{3}$, Nadjla Hariri ${ }^{4}$}

${ }^{1}$ Health Sciences Research Center, Health information technology department, school of Allied Medical Sciences, Mazandaran University of Medical Sciences, kilometer 17 Khazar Abad, Sari, Mazandaran, Iran

${ }^{2}$ Department of Knowledge \& Information Sciences, Faculty of management and Economics, Tarbiat Modares University, Tehran, Iran

${ }^{3}$ Department of Knowledge \& Information Sciences, School of Humanity and Social Sciences, Science and Research Branch, Islamic Azad University, Tehran, Iran.

${ }^{4}$ Department of Knowledge \& Information Sciences, School of Humanity and Social Sciences, Science and Research Branch, Islamic Azad University, Tehran, Iran.

Study Area: Ten Provinces of Iran (Mazandaran, Guilan, Golestan Sistan and Balouchestan, Kermanshah, East Azarbayjan, Tehran, Isfahan, Qom and Semnan)

Key words: Library, Blind information, Audio-visual

\section{Introduction:}

The study was aim to recommend some new model of information seeking behavior for Iranian blind people that extend the concept beyond the simple types of information, seeking to look for other modes of behaviour. Information science has produced numerous models as per information needs. Wilson introduced 'an integrative model of information need, information seeking behaviour and information use (Wilson, 1994). It was a 'person centered model, based largely on 'Dervin's SenseMaking approach'. We attempted in our study to extend Wilson's models, in particular to enhance fully incorporate Dervin's theory of sense making, its portrait of the human and its description towards the conceptual gap between an individual's inner reality and the external reality with which they find themselves confronted. (Godbold, 2006) Being able to use, read and proper understanding communication is not only a precondition to participate in social life; it is also a key to quality of life for the individual. The ability to take part in above processes has become more crucial prerequisite to participate in social life. Comparatively less ability to read

\section{Abstract}

Access to information and its dissemination for the planning of health and social care is essential. While information is not always available as per the needs of the blind people, thus the public libraries and information centers led for meeting the information needs culture and proper knowledge. The study was based on a Descriptiveanalytic method in which we included 384 blind people of both the sex selected by the multi-clustering method from 1o provinces of Iran. Health information of the subjects was collect through a researcher-based questionnaire. Results showed that religion, occupations, and access to healthy living, were the first top priority of blind people for meeting information needs in three cultural; social in addition, health forms. The blind people try to look for information on a daily basis and seeking up-to-date technologies. They are most used to audio media rather than any other media to access, utilise information, and rarely used new technologies. Unlike normal people, blind people have high expectations from the library. An attempt has also been taken to present a new model.

or write at the same level as other normal human beings is a serious disadvantage. In the year 2010, the importance of making information accessible for visually impaired people was realized by different sections in different countries. For example, the UK legislation, the Disability Discrimination Act (The Stationary office 1995) imposed the importance of making information accessible to the visually impaired people. Service providers now have to make "reasonable adjustments" for such special people (Singh \& Moirangthem, 2010).

Based on WHO data, some of the facts and figures are:

- 285 million people are estimated to be visually impaired worldwide: 39 million are blind whereas 246 million havelowvision.

- About 9o\% of the worlds visually impaired live in lowincome settings.

- $82 \%$ of blind people are above 50 years of age 50 .

- Globally, uncorrected refractive errors are the main cause of moderate and severe visual impairment; cataracts remain the leading cause of blindness in middle-and low-income countries.

- The number of people visually impaired from infectious 
diseases has reduced in the last 20 years according to global estimates work.

- $80 \%$ of all visual impairment can be prevented or cured. (World Health Organization, 2014).

\section{Whoareat risk?}

Approximately $90 \%$ of visually impaired people live in developing countries. People aged 50 and over About $65 \%$ of all people who are visually impaired are aged 50 and older, while this age group comprises about $20 \%$ of the world's population. With an increasing elderly population in many countries, more people will be at risk of visual impairment due to chronic eye diseases and ageing processes.

\section{Children below age 15 .}

An estimated 19 million children are visually impaired. Of these, 12 million children are visually impaired due to refractive errors, a condition that could be easily diagnosed and corrected. 1.4 million are irreversibly blind for the rest of their lives and need visual rehabilitation interventions for a full psychological and personal development.

\section{Changes over the last twenty years.}

Overall, visual impairment worldwide has decreased since the early estimates in the 1990s. This is despite an ageing global elderly population. This decrease is principally the result of a reduction in visual impairment from infectious diseases through:

- overall socioeconomic development;

- concerted public health action;

- increased availability of eye care services;

- awareness of the general population about solutions to the problems related to visual impairment (surgery, refraction devices, etc.).

\section{Theglobal response to prevent blindness.}

Globally, $80 \%$ of all visual impairment can be prevented or cured. Areas of progress over the last 20 years include:

- governments established national programmes and regulations to prevent and control visual impairment;

- eye care services increasingly available and progressively integrated into primary and secondary health care systems, with a focus on the provision of services that are high quality, available and affordable;

- campaigns to educate about visual function importance and raise awareness, including schoolbased education; and

- stronger government leadership on international partnerships, with increasing engagement of the private sector.

Data over the last 20 years shows that there has been significant progress in preventing and curing visual impairment in many countries. Furthermore, the massive reduction in onchocerciasis and trachoma-related blindness is part of a significant reduction in the disease distribution and has substantially reduced the burden resulting from these infectious diseases. This has been achieved through a number of successful international public-private partnerships.

Specific achievements include:

- During the last few years, Brazil has been providing eye care services through the national social security system.

- Morocoo which has launched a public effort to control glaucoma.

- China which has invested over 100 million dollars in cataract surgeries since 2009 .

- Oman has completely integrated eye care service provision in the primary health care framework over the last decade.

- India since 1995 has made available funds for eye care service provision for the poorest at the district level.

The largest civil society effort to prevent and cure blinding disease and rehabilitate people whose irreversibly visually impaired or blind is the SightFirst programme of the International Association of the Lions Club (LIONS). Among others, this programme supports the largest initiative to develop child eye care centres ( 45 national reference paediatric centres established in 35 countries so far), implemented in partnership with WHO.

\section{WHOresponse}

WHO coordinates the international efforts to reduce visual impairments? Its role is to:

- monitor the worldwide trends of visual impairment by countryand by region;

- develop policies and strategies to prevent blindness appropriate forvarious development settings; • to give technical assistance to the Member States and partners;

- to plan, monitor and evaluate programmes; and

- to coordinate effective international partnerships in support of national efforts.

In 2013, the World Health Assembly approved the 2014-19 Action Plan for the universal access to eye health, a roadmap for Member States, WHO Secretariat, and international partners with the aim of achieving a measurable reduction of $25 \%$ of avoidable visual impairments by 2019 .

WHO works to strengthen national and country-level efforts to eliminate avoidable blindness, help national health care providers treat eye diseases, expand access to eye health services, and increase rehabilitation for people with residual visual impairment or who are blind. Building accessible and comprehensive health systems are the focus of this decade.

WHO leads several international alliances of governments, the private sector and civil society organizations aiming at contributing to the elimination of blinding diseases. It also provides technical leadership to specific disease efforts which are deployed by its partners 
or the private sector to eliminate trachoma from the world by theyear 2020. For the last two decades WHO has worked with a network of international partners and private sector to ensure that appropriate, updated, good quality eye care solutions were made available to the people in need.

Since 2004, WHO in partnership with Lions Clubs International has established a global network of 45 childhood blindness centers in 35 countries for the preservation, restoration or rehabilitation of sight in children. This unique and innovative global project has served so far more than 150 million children and will open 10 additional eye care service centers for the children in 10 new countries in 2014. The centers will help combat to fight avoidable childhood blindness and help to secure a future with a full visual function for the children in need of care. In response to the increasing burden of chronic eye disease WHO is coordinating a global research effort to map services and policies for controlling diabetic retinopathy, glaucoma, age-related macular degeneration and refractive errors. Finally, to support comprehensive eye care systems, WHO continues to provide epidemiologically and public health technical support to its Member States (WHO, 2014).

As per the US Bureau of the Census, World Population Profile-19981998, in continuation of the usual process, it could be estimated that the number of individuals with blindness might reach up to 6 million by theyear 2020. It is mainly due to the rapid aging of populations in most countries. Since eye diseases are mainly noticed in older people, by 2020 the projected doubling of the world's population, older than 50 years to 2 billion would be profound effects on the number of those with blindness and low vision (Summer, 2004). It was anticipated that many of the incident blinds would not survive because of vitamin A deficiency, so the annual cumulative annual incidence would be only about 200 , ooo per year (Pararajasegaram, 1999). According to statistics obtained from Iranian General Welfare on May 11, 2011, there were 21989 subjects ( 6915 men and 15,074 women were male). In other words, about $0.03 \%$ of the blind population is composed deals that require special services.

\section{Information needs Definition.}

Among various types of needs, the most recognizable need is the 'articulated' or expressed need, which is an actually recognized need that demands an answer Unperceived or unexpressed needs are not recognized as information needs" (Davies, 2007).

\section{Information-Seeking Behaviour definition.}

"Information seeking has been conceptualized in terms of all the ways in which information comes to people, including those which are absorbed passively" (Bates, 2002). Since the mid-1980s, many theoretical models and frameworks have been proposed for information seeking research (Järvelin \& Wilson, 2003). Various theoretical treatments based on complex cognitive process have been proposed to characterize the information-seeking behaviour (Belkin et al., 1995; Ellis, 1993; Järvelin \& Wilson, 2003; Kuhlthau, 1991; Marchionini, 1995; Saracevic \& Kantor, 1997a, 1997b; Sutcliffe et al., 2000) Several instruments for effective information (seeking-) behaviour have already been developed (Cameron \& Harvey, 2006; Carol et al., 2004; Kurbanoglu et al., 2006; Monoi et al.,2005; Van Kampen, 2004).

\section{A model of information behavior}

Till date very limited knowledge, we have regarding the information-seeking behaviour of blind people in worldwide. Research on information-searching behaviour was realized as a sub-set of informationseeking behaviour. It focuses on the interactions between information user and computer-based information systems and thereby corresponds with to the previously mentioned ICT concept of information skills(Boekhorst, 2003) and operational cum formal skills (Van Deursen \& Van Dijk, 2008). The focus on actual behaviour was inspired by Miller's pyramid of competence (Fig.-1), a model frequently used in higher education to classify tests (Van Deursen \& Van Dijk, 20o8). A model may be described as a framework for thinking about a problem and may evolve into a statement of the relationships among theoretical propositions. Most models in the general field of information behaviour are of the former variety: mostly are statements, often in the form of diagrams that attempt to describe an information-seeking activity, the causes, and consequences of that activity, or the relationships among stages in information-seeking behaviour. Rarely such models advance to the stage of specifying relationships among theoretical propositions: rather, they are at a pre-theoretical stage, but may suggest relationships that might be fruitful to explore or test (Wilson, 1999).

\section{Proposed Model for Blind Information Seeking Behavior.}

We used numerous investigation methods and data collection tools and practices in previous studies to identify the characteristics and information-seeking behaviour of the users and relate such behaviour to their characteristics, special blind people.

For extracting pattern from Ph.D. dissertation, we used data that obtained from the questionnaire. In a designing model, we used factor analysis and hidden factors extraction by path analysis. We used elements of fundamental space. For the validity of this model, we evaluated the professional and experts in the fields of Library and Information sciences and Communication sciences (Figure 1 ).

In this paper, he used four terms- information behavior, information seeking behavior, information searching behavior and information use behavior. The 


\section{Hasan Siamian's Blind People Information Executive Recommendations.}

Seeking Behavious Model.

The results showed that achieving a healthy lifestyle,

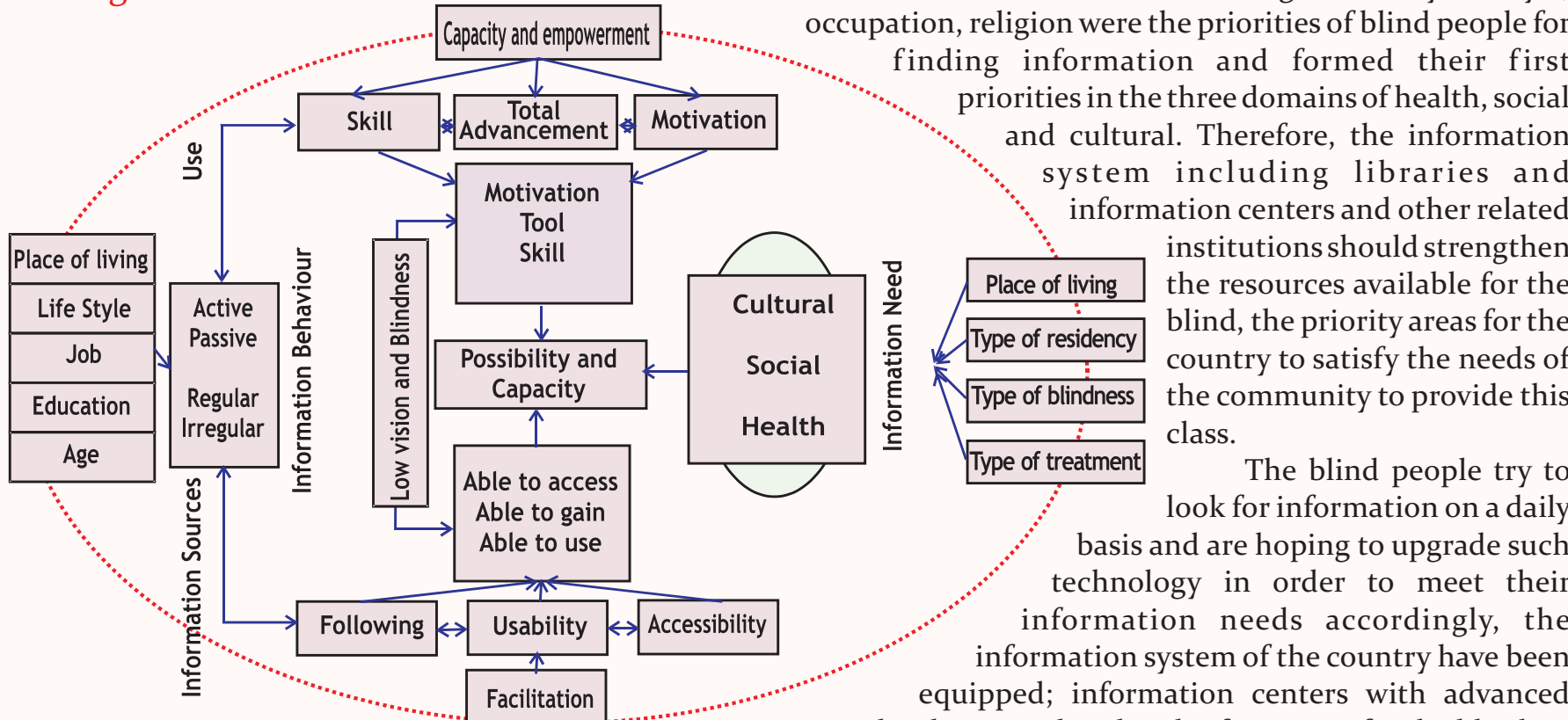

Figure-1: Need level: Place of living/type of residency, type of blindness, type of treatment. Information behaviour level: Age group, Education, Job, Type of living, Place of Residency.

behaviors are defined as follows: Information Behavior is the totality of human behavior in relation to sources and channels of information, including both active and passive information seeking, and information use. Thus, information behavior includes face-to-face communication with others, as well as the passive reception of information, for example, watching TV advertisements, without any intention to act on the information given. Information Seeking Behavior is the purposive seeking for information because of a need to satisfy some goal. In the course of seeking, the individual may interact with manual information systems (such as a newspaper or a library), or with computer-based systems (such as the World Wide Web). Further, Information Searching Behavior is the 'micro-level' of behavior employed by the subject in interacting with information systems of all kinds. As could be realized in the above model, the information behavior shows all components in the form of regular, irregular, active, and passive. The demographic characteristics such as, Information behavior level: age group, education, job profile, living standard, residential status in determining the type of information that should be written to be used for ordinary people forms consider by the designers of information systems and policy makers. Nevertheless, the level of information needs, factors such as Place of living/type of residency, type of blindness, type of treatment as such in every design decision should be considered. technologies and updated information for the blind. In this context, it is suggested the use of specif ic technologies such as telecommunications with the capability of specif ic needs of blind people.

Among specific media types, the blind people mostly access and utilize audio media for information. Our results suggest that like libraries, information centers, and special features to enhance the audio sources and formats for access.

In blind people despite their high interest towards new technologies, they use less than normal use. Therefore, it is necessary to guide them regarding the use of new technologies, which should be available for the blind people in information centers.

Unlike ordinary people, blind people have high needs and expectations about libraries. In contrast, the estimated rate expectations, the level of their satisfaction concerning libraries' service is very low. Accordingly, furnishing the special section for disabled especially for the blind people in libraries can provide proper use of blind peopleas a part of the community.

No Specific library, information centers, and library professionals for blind people are available. Accordingly, it is suggested that the current Blind unit in National Library of Iran promote "deputy" or "general administration services for people with disabilities." Information needs and behavior of blind people vary based on place of living, type of residence, type of blindness and treatment. Accordingly, practitioners and managers of information systems must consider in any policy making, planning and executing these variables in Iran.

On one side, the blind people rely on family and friends to access their information; on the other, this way is 
not enough for them to get information. Accordingly, the information centers such as libraries besides equipping and establishing services and training blind people must have plans for training their families as well as blind people.

\section{Acknowledgements:}

This paper is based on $\mathrm{PhD}$ of dissertation of library and information sciences (knowledge and Information Science) at Islamic Azad University, Research Science Branch, Tehran, Iran. The model presented in this article is those of concluded data, factoranalyses of the information behaviors.

\section{References:}

Bates, M.J. (2002): Toward an integrated model of information seeking and searching. The New Review of Information Behaviour Research, 3:1-15.

Belkin, N.J, Cool, C., Stein, A.,, \& Thiel, U. (1995): Cases, scripts, and information-seeking strategies: On the design of interactive information retrieval systems. Expert Sy. applic., 9(3), 379-395.

Boekhorst, A.K. (2003): Becoming information literate in the Netherlands. Lib. Rev., 52(7), 298-309.

Cameron, D, \& Harvey, A. (2006). eHEALS: The eHealth Literacy Scale. J. Med. Internet Res., 8(4), e27.

Davies, K. (2007): The information-seeking behaviour of doctors: a review of the evidence. Health Info. Lib. J., 24(2), 78-94.

Ellis, D. (1993): Modeling the information-seeking patterns of academic researchers: A grounded theory approach. Lib. Quart., 469-486.

Godbold, N. (2006): Beyond information seeking towards a general model of information behaviour. Info. Res., 11(4), Paper 269

Järvelin, K., \& Wilson, T.D. (2003): On conceptual models for information seeking and retrieval research $\underline{I n f o . ~ R e s ., ~ 9(11), ~}$ paper 163.

Kuhlthau, C.C. (1991): Inside the search process: information seeking from the user's perspective. I. Ame. Soc. Inf. Sci., 42(5), 361-371.

Kuhlthau, C.C. (2004): Seeking meaning: A process approach to library and information services: Libraries Unltd Incorporated.
Kurbanoglu, S.S., Akkoyunlu, B., \& Umay, A.. (2006). Developing the information literacy self-eff icacy scale. I. Doc., 62(6), 730743.

Marchionini, G. (1995): Information seeking in electronic environments. Cambridge University Press.

Monoi, S., O'Hanlon, N., \& Diaz, K.R. (2005): Online searching skills: Development of an inventory to assess self-eff icacy. L. Acad. Librarianship., 31(2), 98-105.

Pararajasegaram, R. (1999): VISION 2020-The Right to Sight: from strategies to action. Am. J. Ophthalmol., 128359- 128(3)359360.

Saracevic, T., \& Kantor, P.B. (1997a): Studying the value of library and information services. Part I. Establishing a theoretical framework. J. Ame. Soc. Inf. Sci., 48(6), 527-542.

Saracevic, T., \& Kantor, P.B. (1997b): Studying the value of library and information services. Part II. Methodology and taxonomy. J. Ame. Soc. Info. Sci., 48(6):543-563.

Singh, KP, \& Moirangthem, E.. (2010): Are Indian Libraries VIPFriendly? Information Use and Information Seeking Behaviour of Visually Impaired People in Delhi Libraries. Libr. Philos. Pract. (e-journal), 374.

Summer, A. (2004): Global Health, Global Vision. Arch Ophthal., 122:911-912.

Sutcliffe, A. G., Ennis, M., \& Watkinson, S. J. (2000): Empirical studies of end-user information searching. L. Ame. Soc. Inf. Sci., 51(13):1211-1231.

Van Deursen, A.J.A.M., \& Van Dijk, J.A.G.M. (2008): Measuring digital skills. Paper presented at the The Conference of the International Communication Association, Montreal, Canada.

Van Kampen, D.J. (2004): Development and validation of the multidimensional library anxiety scale. Coll. Research Libr. 65(1):28-34

Wilson, T. (1994): Information needs and uses: fifty years of progress. Fifty years of information progress. L. Documen.Rev., 4:15-51.

Wilson, T.D. (1999): Models in information behaviour research. J. Documen., 55(3):249-270.

WHO (World Health Organization) (2004): Visual impairment and blindness.Fact Sheet $\mathrm{N}^{\circ} 282$. Updated August 2014 Retrieved 25 July 2016, 2014, from avaiable online at: http://www.who.int/mediacentre/factsheets/fs282/en/ 